\title{
Trypsin-like serine peptidase profiles in the egg, larval, and pupal stages of Aedes albopictus
}

Leonardo Saboia-Vahia', André Borges-Veloso', Camila Mesquita-Rodrigues ${ }^{1}$, Patricia Cuervo², Geovane Dias-Lopes ${ }^{1}$, Constança Britto ${ }^{1}$, Ana Paula de Barros Silva ${ }^{1}$ and Jose B De Jesus ${ }^{1,3^{*}}$

\begin{abstract}
Background: Aedes albopictus, a ubiquitous mosquito, is one of the main vectors of dengue and yellow fever, representing an important threat to public health worldwide. Peptidases play key roles in processes such as digestion, oogenesis, and metamorphosis of insects. However, most of the information on the proteolytic enzymes of mosquitoes is derived from insects in the adult stages and is often directed towards the understanding of blood digestion. The aim of this study was to investigate the expression of active peptidases from the preimaginal stages of Ae. albopictus.
\end{abstract}

Methods: Ae. albopictus eggs, larvae, and pupae were analyzed using zymography with susbtrate-SDS-PAGE. The $\mathrm{pH}$, temperature and peptidase inhibitor sensitivity was evaluated. In addition, the proteolytic activities of larval instars were assayed using the fluorogenic substrate Z-Phe-Arg-AMC.

Results: The proteolytic profile of the larval stage was composed of 8 bands ranging from 17 to $130 \mathrm{kDa}$. These enzymes displayed activity in a broad range of pH values, from 5.5 to 10.0. The enzymatic profile of the eggs was similar to that of the larvae, although the proteolytic bands of the eggs showed lower intensities. The pupal stage showed a complex proteolytic pattern, with at least 6 bands with apparent molecular masses ranging from 30 to $150 \mathrm{kDa}$ and optimal activity at $\mathrm{pH} 7.5$. Peptidases from larval instars were active from $10^{\circ} \mathrm{C}$ to $60^{\circ} \mathrm{C}$, with optimal activity at temperatures between $37^{\circ} \mathrm{C}$ and $50^{\circ} \mathrm{C}$. The proteolytic profile of both the larval and pupal stages was inhibited by phenyl-methyl sulfonyl-fluoride (PMSF) and Na-Tosyl L-lysine chloromethyl ketone hydrochloride ( $T L C K)$, indicating that the main peptidases expressed during these developmental stages are trypsin-like serine peptidases.

Conclusion: The preimaginal stages of Ae. albopictus exhibited a complex profile of trypsin-like serine peptidase activities. A comparative analysis of the active peptidase profiles revealed differential expression of trypsin-like isoforms among the preimaginal stages, suggesting that some of these enzymes are stage specific. Additionally, a comparison of the peptidase expression between larvae from eggs collected in the natural environment and larvae obtained from the eggs of female mosquitoes maintained in colonies for a long period of time demonstrated that the proteolytic profile is invariable under such conditions.

Keywords: Aedes albopictus, Culicidae, Preimaginal stages, Trypsin-like serine peptidases, Peptidases, Zymography

\footnotetext{
*Correspondence: jbj@ioc.fiocruz.br

'Laboratório de Biologia Molecular e Doenças Endêmicas, Instituto Oswaldo

Cruz, FIOCRUZ, Rio de Janeiro, Brazil

${ }^{3}$ Departamento de Engenharia de Biossistemas, Universidade Federal de São

João Del Rey, Minas Gerais, Brazil

Full list of author information is available at the end of the article
} 


\section{Background}

During the last three decades, the mosquito Aedes (Stegomyia) albopictus has spread from Southeast Asia to Africa, the Middle East, Europe and America. This species has demonstrated a strong ecological plasticity that allows for rapid adaptation to diversified habitats, including urban environments [1-6]. Female oviposition occurs in both natural conditions and in artificial containers, and it has been reported that Ae. albopictus successfully compete against other container-breeding mosquitoes, including Ae. aegypti [5,7]. Ae. albopictus is a competent vector for at least 22 arboviruses and plays significant role in the transmission of all four serotypes of the dengue virus as well as in the transmission of nematodes, such as Dirofilaria immitis and Dirofilaria repens [5,8-12].

The secretion of serine peptidases responsible for the hydrolysis of nutrients from food was first reported for Ae. aegypti in the early 1970s [13]. Furthermore, serine peptidases have been implicated in the regulation of immunity in Anopheles sp. [14-16]. Within the serine peptidase family, trypsin and chymotrypsin are the most abundant digestive enzymes in the midgut of several insect species [17]. These enzymes are characterized as having a His-Asp-Ser catalytic triad and the same basic tridimensional structure, consisting of two six-stranded $\beta$-barrels that contain the active site, the substrate recognition region and the zymogen activation domain [18]. Despite the high similarity of serine peptidases among mosquito species, each enzyme has a unique set of accessory catalytic residues that are thought to be important for determining substrate specificity $[19,20]$.

Previous studies have reported the proteolytic activity of both trypsin and chymotrypsin in the peritrophic matrix and gut of Ae. aegypti, Ae. albopictus and Culex quinquefasciatus larvae [21-23]. These enzymes have also been associated with the digestion of nutrients by larvae of other diptera species, such as Dermatobia hominis, Lutzomya longipalpis, Musca domestica, and Oxysarcodexia thornax [24-27]. In addition, trypsins secreted in the lumen of the gut have been implicated in the process of pathogen establishment in vector mosquitoes. For example, trypsins secreted by the mosquito for food digestion are involved in the activation of the proenzyme form of a chitinase from the Plasmodium species [28-32]. Moreover, arboviruses such as the La Crosse virus (LACV; Bunyaviridae), blue tongue virus (BTV; Reoviridae) and dengue virus serotype 2 (DENV-2, Flaviviridae) use vector midgut peptidases for the proteolytic processing of viral proteins to increase viral infectivity [33-35].

The current study aims to characterize and compare the serine-peptidase proteolytic profiles of the egg, four larval instars and the pupal stage of Ae. albopictus using substrate SDS-PAGE zymographic analysis.

\section{Methods}

\section{Chemicals}

All chemicals were purchased from Sigma Chemical Company (USA). Stock solutions of No-Tosyl-L-lysine chloromethyl ketone hydrochloride (TLCK, $100 \mathrm{mM}$ ) and $\mathrm{N}$ - $p$-Tosyl-L-phenylalanine chloromethyl ketone (TPCK, $100 \mathrm{mM}$ ) were prepared in methanol. Phenylmethyl sulfonyl-fluoride (PMSF, $250 \mathrm{mM}$ ) was diluted in isopropanol, whereas 1,10-phenantroline (200 mM) and pepstatin A $(1 \mathrm{mg} / \mathrm{ml})$ were dissolved in ethanol. Trans-epoxysuccinyl L-leucylamido-(4-guanidino) butane $(\mathrm{E}-64,10 \mu \mathrm{M})$ was prepared in water. The stock solution of Z-carbobenzoxy-L-phenylalanyl-L-arginine(7-amino-4-methylcoumarin) [Z-Phe-Arg-AMC] (3 mM) was prepared in dimethylsulfoxide (DMSO).

\section{Insects}

Pre-imaginal stages (eggs, larvae and pupae) of Ae. albopictus used in the present study came from two sources: (i) a closed continuous colony (Laboratório de Transmissores de Hematozoários, Instituto Oswaldo Cruz, FIOCRUZ, Rio de Janeiro) originated from insects captured in the Brazilian state of Rio de Janeiro, and (ii) F1 generation of larvae hatched from eggs collected by ovitraps in the natural environment in endemic areas of Rio de Janeiro. In the closed colony, eggs (two days old), larvae (first larval instar, L1; second larval instar, L2; third larval instar, L3; and forth larval instar, L4) and pupae $\left(16-20 \mathrm{~h}\right.$ old) were reared at $28 \pm 1^{\circ} \mathrm{C}$ under $80 \pm 10 \%$ relative humidity, with a photoperiod of 12:12 h (LD). The larvae were kept in plastic basins containing dechlorinated water and were fed with fish food $\left(\right.$ Tetramin $\left.^{\circledR}\right)$. The F1 generation of larvae hatched from eggs collected by ovitraps in the natural environment in endemic areas of Rio de Janeiro was used to compare with larvae obtained from the eggs of female mosquitoes maintained for a long period of time in the closed continuous colony. The ovitrap consist in a plastic vase with a wooden oviposition paddle and hay infusion as described previously [36]. The paddles with eggs from the field were placed in plastic basins to hatch and the larvae were reared up until the fourth instar for identification using the key by Consoli \& Lourenço-de-Oliveira [37]. The L4 larvae were separated from the others and reared up until imaginal stages for $\mathrm{F} 1$ eggs collection. $\mathrm{F}_{1}$ larvae were reared in the same conditions as mentioned above.

\section{Protein extraction and quantification}

The larvae and pupa of Ae. albopictus were washed twice in PBS buffer ( $\mathrm{pH}$ 7.2). Then, they were mechanically disrupted in lysis buffer containing $10 \%$ glycerol, $0.6 \%$ Triton $\mathrm{X}-100,100 \mathrm{mM}$ Tris- $\mathrm{HCl}$ and $150 \mathrm{mM}$ $\mathrm{NaCl}$. Protein was extracted from the eggs by five cycles 
of freezing and thawing in liquid nitrogen, followed by mechanical disruption in the same lysis buffer. The extracts were then centrifuged at $14000 \times g$ for 10 minutes at $4^{\circ} \mathrm{C}$ to remove insoluble material. Total protein was quantified using a commercial kit (Pierce Protein assay), according to the manufacturer's instructions.

\section{Zymographic assays}

To investigate the proteolytic profile of total extracts, $30 \mu \mathrm{g}$ of protein were subject to electrophoresis $(110 \mathrm{~V}$ at $4{ }^{\circ} \mathrm{C}$ ) on $12 \%$ SDS-PAGE gels copolymerized with $0.1 \%$ porcine gelatin. After electrophoresis, the resulting gels were washed twice for 30 minutes at $4^{\circ} \mathrm{C}$ in $0.1 \mathrm{M}$ sodium acetate buffer ( $\mathrm{pH} 3.5$ or 5.5 ) containing $2.5 \%$ Triton X-100, or in $0.1 \mathrm{M}$ Tris- $\mathrm{HCl}$ buffer $(\mathrm{pH} 7.5$ or 10 ) containing $2.5 \%$ Triton X-100. Proteolytic activity was detected after incubating the gels at $37^{\circ} \mathrm{C}$ in reaction buffer containing $0.1 \mathrm{M}$ sodium acetate $(\mathrm{pH} 3.5$ or 5.5$)$, or in $0.1 \mathrm{M}$ Tris-HCl buffer ( $\mathrm{pH} 7.5$ or 10). Gels loaded with egg protein were incubated for 120 minutes, whereas gels loaded with larvae protein were incubated for $30,60,120$ or 180 minutes. Pupal enzymes were incubated for $3,6,12,24,36$ or $48 \mathrm{~h}$. Bands of gelatin degradation were visualized by staining the gels with $0.25 \%$ Coomassie blue R-250 and subsequent destaining with $10 \%$ acetic acid. The molecular mass of the proteases was calculated by comparison with the mobility of a commercial molecular mass standard. All results are derived from five independent experiments carried out in triplicate.

\section{Effect of temperature on the proteolytic activities of larvae}

The thermal sensitivity of larval peptidase activities was evaluated by incubating gels at $4^{\circ} \mathrm{C}, 10^{\circ} \mathrm{C}, 37^{\circ} \mathrm{C}, 50^{\circ} \mathrm{C}$, and $60^{\circ} \mathrm{C}$ in $0.1 \mathrm{M}$ Tris- $\mathrm{HCl}$ buffer (pH 7.5). Prior to gel electrophoresis, the protease extracts were incubated until they reached the proper temperature for the assay. In addition, after electrophoresis, the gels were incubated in reaction buffer that was adjusted to each temperature.

Zymographic analysis of peptidase profiles of larvae from eggs collected from the natural environment vs. larvae from eggs of a colony maintained for a long period

For this assay, two different types of Ae. albopictus larvae were used: (i) larvae from eggs collected in the natural environment in endemic areas of Rio de Janeiro and (ii) larvae obtained from the eggs of female mosquitoes maintained for a long period of time in a closed continuous colony. Larvae hatched from both types of eggs ( $\mathrm{i}$ and ii) were prepared for zymography as previously described.

\section{Protease inhibition assays}

Larvae and pupa homogenates were pre-incubated (before electrophoresis) for $30 \mathrm{~min}$ at $4{ }^{\circ} \mathrm{C}$ with one of the following peptidase inhibitors: $10 \mu \mathrm{M}$ E-64, $1 \mathrm{mM}$ PMSF, $100 \mu \mathrm{M}$ TLCK, $100 \mu \mathrm{M}$ TPCK, $10 \mu \mathrm{M}$ pepstatin-A or $10 \mathrm{mM}$ 1,10-phenanthroline. After electrophoresis, each inhibitor, at the same concentration, was also added to the reaction buffer. Peptidase activities were then resolved as described previously.

\section{In-solution enzymatic assays}

Peptidase activity from larval homogenates was determined by in-solution assays using the fluorogenic substrate Z-Phe-Arg-AMC in the presence or absence of TLCK. One hundred micromolar of substrate was used as a working solution for each assay. The reactions were initiated by diluting $10 \mu \mathrm{g}$ of protein from the larvae of each instar in $100 \mathrm{mM}$ sodium phosphate buffer ( $\mathrm{pH}$ 7.5). The fluorescence intensity was measured every $5 \mathrm{~min}$ during $60 \mathrm{~min}$ by spectrophotofluorometry (SpectraMax Gemini XPS, Molecular Devices, CA) using excitation and emission wavelengths of 380 and $460 \mathrm{~nm}$, respectively. All assays were performed at $37^{\circ} \mathrm{C}$ and $\mathrm{pH}$ 7.5. Controls lacking either the enzyme or the substrate were also included. All results are derived from three independent experiments performed in triplicate.

\section{Results}

Time course of proteolytic activities from larval instars and influence of $\mathrm{pH}$ and temperature on the zymographic profile

The zymographic profile from L1, L2, L3 and L4 larval instars was analyzed after 30, 60, 120 and 180 minutes of incubation at $37^{\circ} \mathrm{C}$ and $\mathrm{pH} 7.5$ to evaluate the influence of time on their enzymatic activities (Figure 1A). We found that the intensity of proteolytic activities increased progressively from 30 to 180 minutes of incubation. The proteolytic profile was composed of at least eight bands ranging in size from 17 to $130 \mathrm{kDa}$. The influence of $\mathrm{pH}$ on the proteolytic activities of larval instars was evaluated after incubation of the gels for two hours in different reaction buffers ranging from $\mathrm{pH} 3.5$ to 10 (Figure $1 \mathrm{~B}$ ). Although enzymatic activities were detected at all $\mathrm{pH}$ condition, the intensity of peptidase activities was reduced at $\mathrm{pH} 3.5$ and 5.5. The thermal sensitivity of peptidases from larval homogenates was measured at $\mathrm{pH} 7.5$ and temperatures of $4^{\circ} \mathrm{C}, 10^{\circ} \mathrm{C}$, $37^{\circ} \mathrm{C}, 50^{\circ} \mathrm{C}$ and $60^{\circ} \mathrm{C}$. At $4^{\circ} \mathrm{C}$ little activity was observed (data not shown) whereas at $10^{\circ} \mathrm{C}$ the proteolytic activities were less intense compared to those visualized at the standard temperature $37^{\circ} \mathrm{C}$. At $50^{\circ} \mathrm{C}$, the enzymatic activities were strongly increased to the extent that some of the proteolytic halos overlapped in the L2, L3 and L4 instars. Conversely, some bands between $40 \mathrm{kDa}$ and 


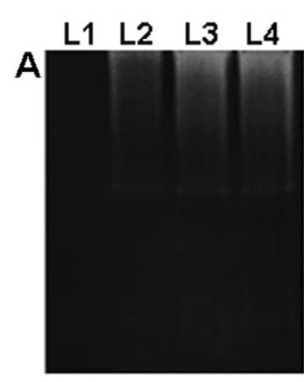

$30 \mathrm{~min}$

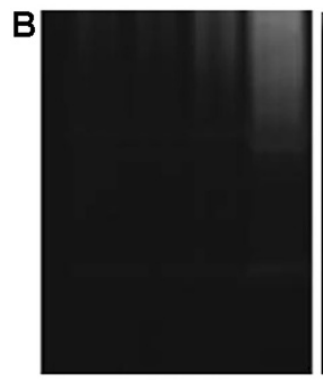

$\mathrm{pH} 3.5$

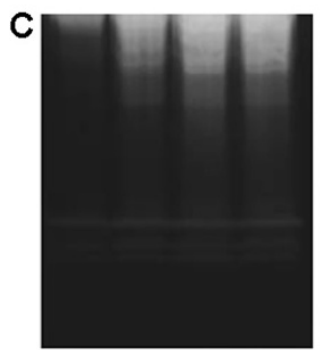

$10^{\circ} \mathrm{C}$

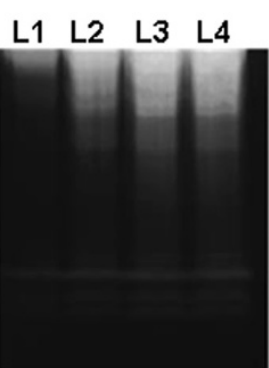

$60 \mathrm{~min}$

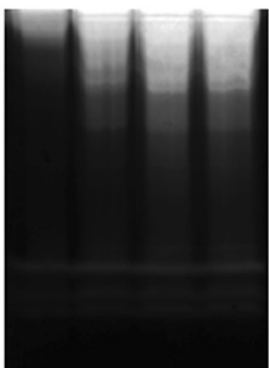

pH 5.5

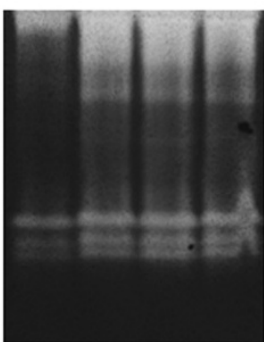

$37^{\circ} \mathrm{C}$

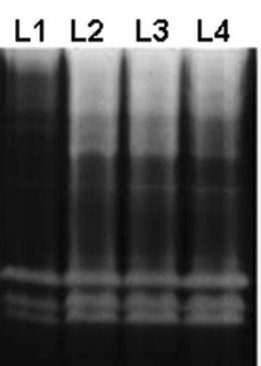

$120 \mathrm{~min}$

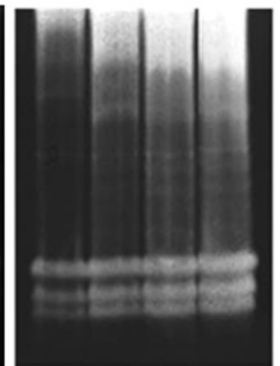

$\mathrm{pH} 7.5$

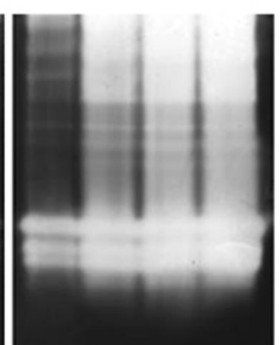

$50^{\circ} \mathrm{C}$

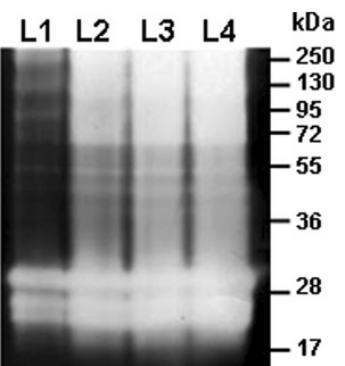

$180 \mathrm{~min}$

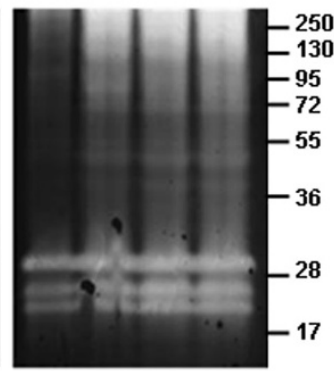

$\mathrm{pH} 10.0$

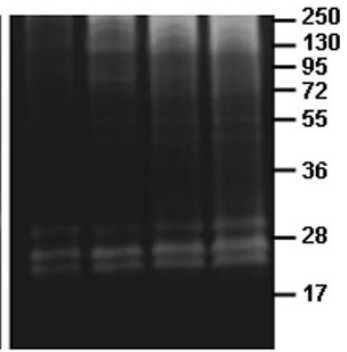

$60^{\circ} \mathrm{C}$

Figure 1 Time course of the proteolytic activities exhibited by the four larval instars of Ae. albopictus and influence of $\mathrm{pH}$ and temperature on the proteolytic profiles. A. Proteolytic activities were evaluated after $30 \mathrm{~min}, 60 \mathrm{~min}, 120 \mathrm{~min}$ and $180 \mathrm{~min}$ of incubation in $0.1 \mathrm{M}$ Tris- $\mathrm{HCl}$ buffer $\left(\mathrm{pH}\right.$ 7.5). B. The effect of $\mathrm{pH}$ on the proteolytic activities was evaluated by incubation at $37^{\circ} \mathrm{C}$ for two hours in $0.1 \mathrm{M}$ sodium acetate buffer $\mathrm{pH} 3.5,5,5$ or $0.1 \mathrm{M}$ Tris- $\mathrm{HCl}$ buffer $\mathrm{pH} 7.5,10.0$. C. Enzyme activities were detected after incubating the gels for 2 hours at $10^{\circ} \mathrm{C}$, $37^{\circ} \mathrm{C}, 50^{\circ} \mathrm{C}$, and $60^{\circ} \mathrm{C}$ in $0.1 \mathrm{M}$ Tris- $\mathrm{HCl}$ buffer ( $\mathrm{pH} 7.5$ ). L1, first larval instar; L2, second larval stage; L3, third larval instar; and $\mathrm{L} 4$, fourth larval instar. The numbers on the right indicate the apparent molecular masses of the peptidases $(k D a)$.

$130 \mathrm{kDa}$ were more visible at $50^{\circ} \mathrm{C}$ in the $\mathrm{L} 1$ instar. At $60^{\circ} \mathrm{C}$, the enzymatic activities were reduced compared to the standard condition (Figure 1C).

Peptidase inhibition assays in larval instars and insolution detection of proteolytic activity

The proteolytic activities of all larval instars were inhibited by $1 \mathrm{mM}$ PMSF and $100 \mu \mathrm{M}$ TLCK (Figure 2A). The zymographic profile was not affected by $10 \mu \mathrm{M}$ E-64 (Figure 2A), $100 \mu \mathrm{M}$ TPCK, $10 \mu \mathrm{M}$ pepstatin A or $10 \mathrm{mM}$ 1,10-phenanthroline (data not shown). Protein extracts from larval instars were used to determine in-solution peptidase activities using the fluorogenic substrate Z-Phe-Arg-AMC in the presence or absence of TLCK, a specific inhibitor of trypsin-like serine peptidases. The enzymatic activities increased progressively from L1 to L4, and each instar displayed different velocities of substrate degradation. All enzymatic activities were strongly inhibited by TLCK (Figure 2B).

Comparative analysis of the peptidase profiles of larvae from eggs collected from the natural environment vs. larvae from eggs collected from a colony maintained for a long period of time

To evaluate the stability of the peptidase activities detected by zymography, the proteolytic profile from larval instars was verified by comparing the enzymatic activities of larvae from eggs collected in the natural environment and larvae obtained from eggs collected 


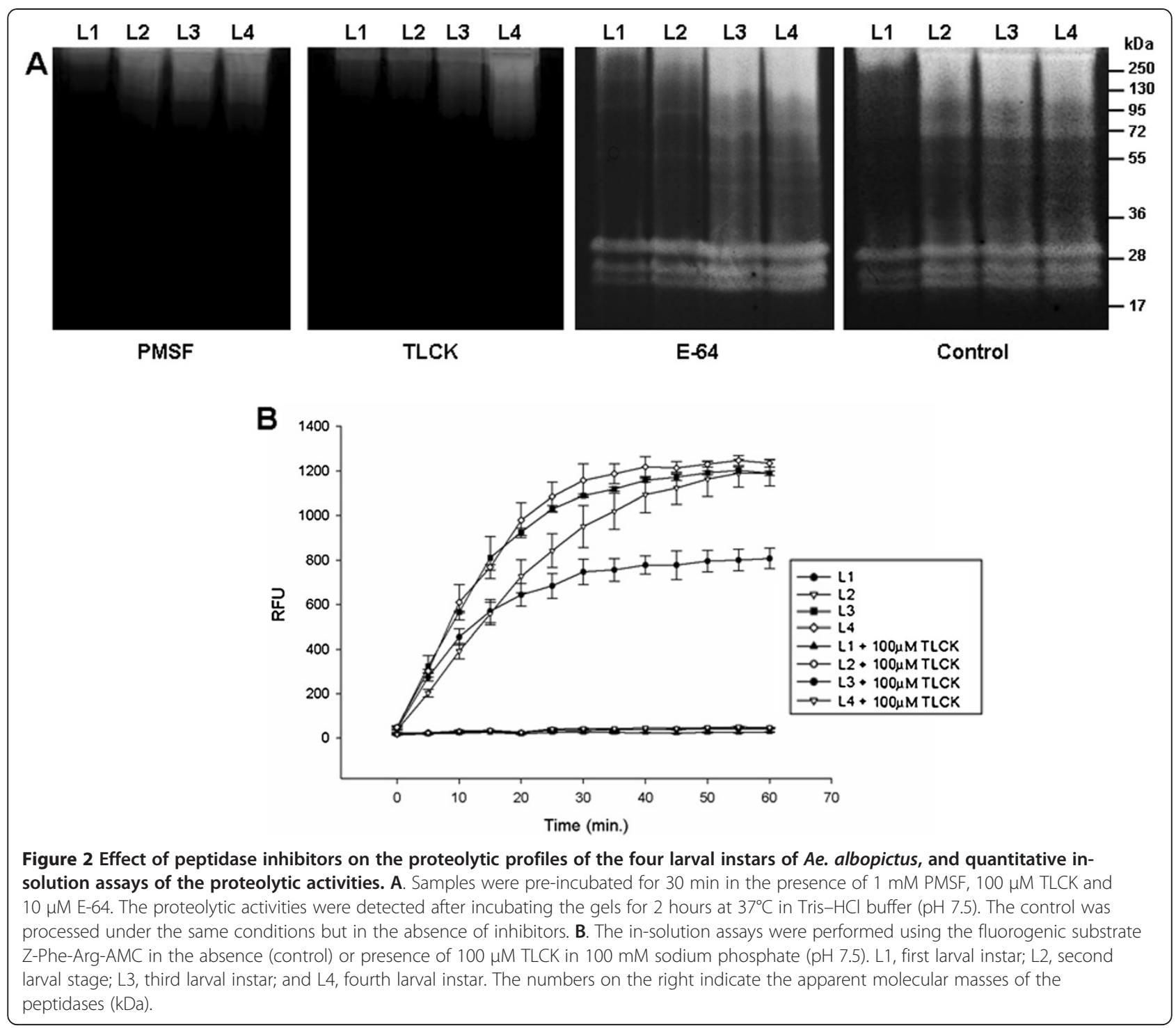

from female mosquitoes maintained in colonies for a long period of time. The larval instars obtained from eggs under both conditions exhibited similar proteolytic profiles (Figure 3).

\section{Comparison of peptidase profiles from eggs and larval instars}

The proteolytic profile displayed by eggs exhibited bands between 17 and $130 \mathrm{kDa}$. The intensity of the proteolytic activities from eggs was lower than those from larvae; however, bands ranging from 72 to $130 \mathrm{kDa}$ were better visualized in the egg extracts compared to the larval extracts. The high molecular weight bands were not well resolved in the proteolytic profiles of the larval instars, likely due to the extremely high enzymatic activity in this area (Figure 4).
Time course of proteolytic activities from the pupal stage and influence of $\mathrm{pH}$ on the zymographic profile

Proteolytic activity from the pupal stage was assessed after $3,6,12,24,36$ and $48 \mathrm{~h}$ of incubation at $37^{\circ} \mathrm{C}$ and $\mathrm{pH}$ 7.5. Enzymatic activity was not detected after 3, 6 or $12 \mathrm{~h}$ of incubation (data not shown and Figure $5 \mathrm{~A}$ ). In contrast, the intensity of the proteolytic activity increased progressively from 24 to $48 \mathrm{~h}$ (Figure $5 \mathrm{~A}$ ). The peptidase profile was well-resolved after $36 \mathrm{~h}$ of reaction, with nearly six evident bands of activity detected between 30 and $200 \mathrm{kDa}$. The proteolytic profile from the pupal stage was analyzed after $36 \mathrm{~h}$ of incubation in different buffers at $\mathrm{pH}$ 3.5, 5.5, 7.5 and 10 (Figure 5B). No enzymatic activity was observed at $\mathrm{pH} 3.5$, while weak proteolytic activity was detected at $\mathrm{pH}$ 5.5. The peptidase profile was best resolved at $\mathrm{pH}$ 7.5. At $\mathrm{pH}$ 10, the proteolytic halos of gelatin degradation overlapped, 


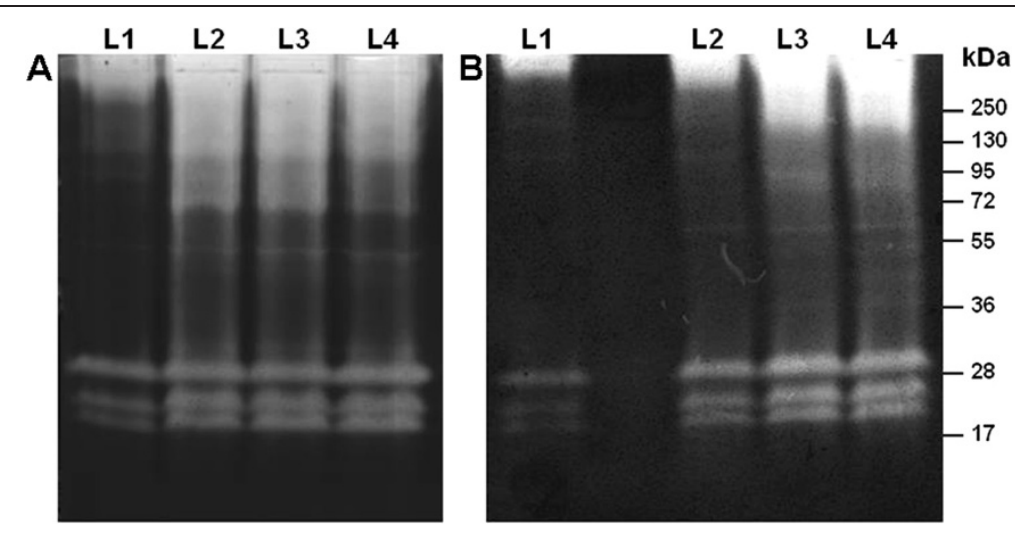

Figure 3 Comparative analysis of the proteolytic profile of Ae. albopictus larvae from (A) eggs obtained from the natural environment in endemic regions of Rio de Janeiro and (B) eggs obtained from colonies maintained for a long time period. Proteolytic activities were detected after incubating the gels for 2 hours at $37^{\circ} \mathrm{C}$ in $0.1 \mathrm{M}$ Tris- $\mathrm{HCl}$ buffer $(\mathrm{pH} 7.5)$. The numbers on the right indicate the apparent molecular masses of the peptidases $(\mathrm{kDa})$.

making it impossible to visualize defined bands, except for one band migrating at $30 \mathrm{kDa}$.

\section{Peptidase inhibition assays in the pupal stage}

The enzymatic profile exhibited by pupal homogenates was strongly inhibited by $1 \mathrm{mM}$ PMSF and $100 \mu \mathrm{M}$ TLCK (Figure 6). Proteolytic activities were not affected by $10 \mu \mathrm{M}$ E-64, $100 \mu \mathrm{M}$ TPCK, $10 \mu \mathrm{M}$ pepstatin A, or $10 \mathrm{mM} \mathrm{1,10-phenantroline} \mathrm{(data} \mathrm{not} \mathrm{shown).}$

\section{Discussion}

Most of the information on the proteolytic enzymes of mosquitoes is comprised from data collected at the adult stages and is often directed towards the understanding of

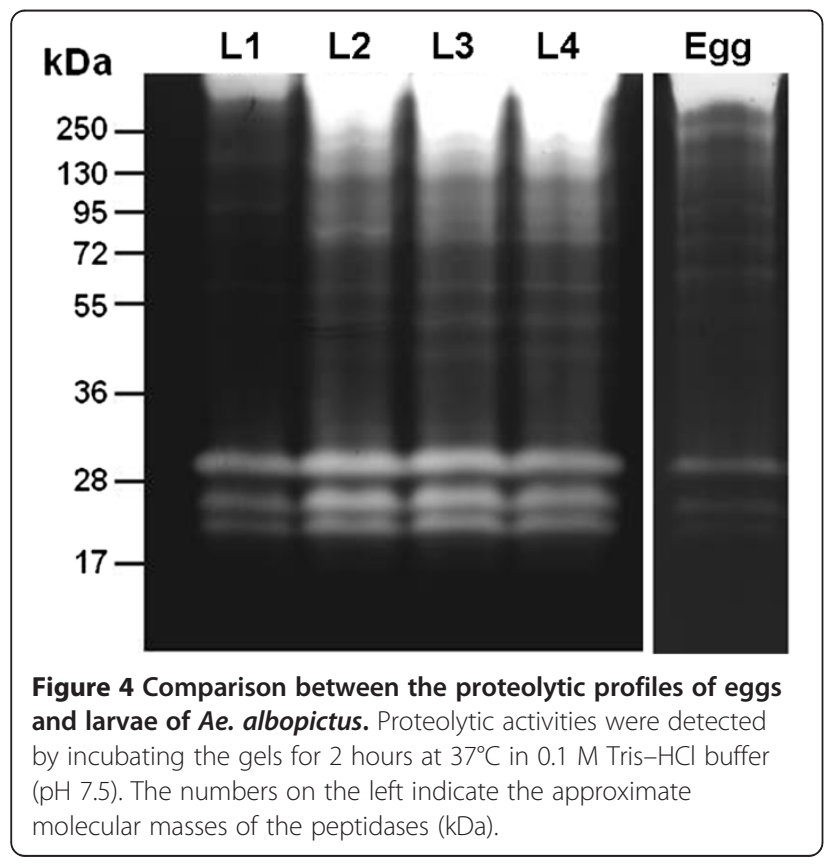

blood digestion [38-40]. The aim of this study was to investigate the expression of active peptidases from the preimaginal stages of Ae. albopictus. To this end, we characterized the proteolytic profile from whole extracts of eggs, larvae and pupae using SDS-substrate gel. The peptidase activities were dependent on the time, $\mathrm{pH}$ and temperature of incubation. The proteolytic profile from all of the analyzed stages was composed primarily of trypsinlike serine peptidases, and each stage exhibited a specific and complex profile of these enzymes. Additionally, a comparison of the peptidase expression between the larvae from eggs collected from a natural environment and larvae obtained from eggs of female mosquitoes maintained in colonies for a long period of time showed that the proteolytic profile is invariable under these conditions.

Although the genome of Ae. albopictus has not yet been completely sequenced, the expression of multiples genes coding for trypsin-like serine peptidases has been reported in the genome of different mosquitoes species, such as Anopheles gambiae, Ae. aegypti and Culex quinquefasciatus, accounting for 345, 380 and 403 putative genes, respectively [41-44]. Compared to other diptera species, such as Drosophila melanogaster, which has 260 genes encoding trypsin-like serine peptidases, the mosquito genome exhibits a larger genetic repertoire of these genes, likely due to gene expansion events [45,46]. The maintenance of a variety of trypsin-like coding genes may be related to their key role in numerous physiological processes of the insect, such as digestion, immunity, reproduction, development, signal transduction and wound healing [47-52]. However, the characterization of active trypsin-like peptidases is scarce, and little is known about the biochemical nature of these enzymes in the preimaginal stages.

In the present study, we observed that Ae. albopictus larval instars displayed a clear proteolytic pattern that 


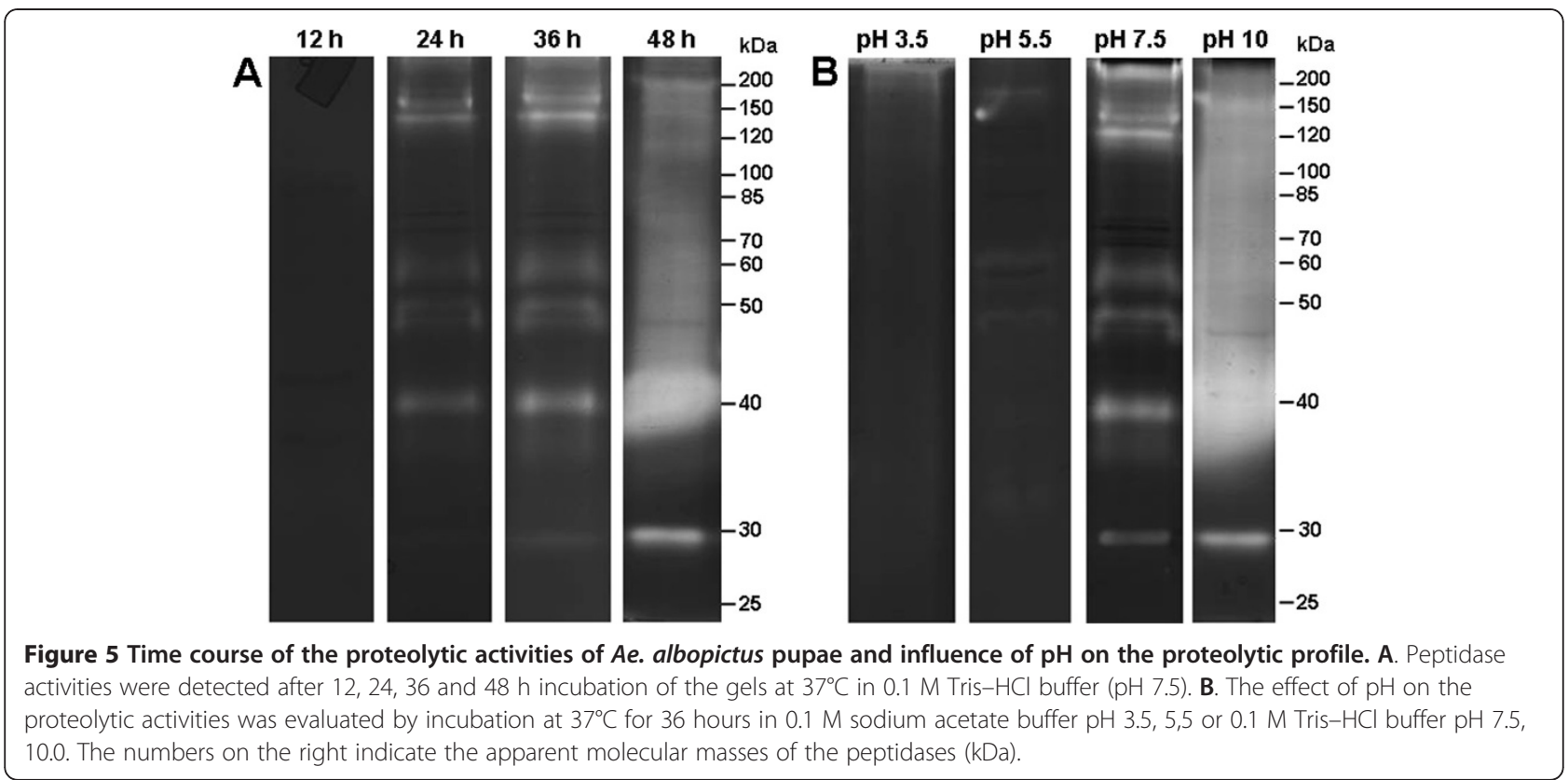

was detected after 2 hours of reaction. In contrast, it has been reported that Ae. aegypti exhibits a zymographic profile after only 1 hour of reaction [22]. These results suggest that the larval peptidases in these species present (i) distinct kinetic activities or (ii) differential quantitative expression. Such differences could also be related to species-specific nutritional characteristics of the larvae. In this regard, the larvae of Ae. albopictus feed more slowly and eat smaller amounts of nutrients at one time compared to the larvae of Ae aegypti [21]. This slower intake of food could lead to slower or reduced activation/expression of peptidases involved in nutrient digestion. Post-feeding induction of peptidase expression has been observed, particularly in adults of Ae. aegypti [53-55]. Here, zymographic analyses revealed that the expression of peptidases increases at each larval instar. This result was corroborated by the quantitative in-solution assays using the fluorogenic substrate ZPhe-Arg-AMC. Quantitative differential expression in larval instars has also been observed by other authors, specifically in the intestine, using alternative methods $[21,39,56]$. In the present study, the proteolytic classes of the enzymes were characterized using different inhibitors, revealing that peptidases from the four larval instars were inhibited by PMSF, an inhibitor of trypsin and chymotrypsin, and TLCK, an inhibitor of trypsin. These results indicate that the enzymes were predominantly trypsin-like serine peptidases in larval instars of Ae. albopictus, which is in agreement with previous descriptions that suggest the occurrence of trypsin in other species from diptera [13,21,24,25,57]. Although no other peptidase classes were detected under the conditions used here, we cannot rule out the possibility that other classes of peptidases could be detected under different experimental conditions.

The four larval instars of Ae. albopictus showed proteolytic activity in a broad range of $\mathrm{pH}$ values, with optimal activity between $\mathrm{pH} 7.5$ and 10. Accordingly, the larvae of Ae. aegypti, An. stephensi and Cx. quinquefasciatus displayed high enzymatic activities at an alkaline $\mathrm{pH}[22,23,58]$. These strong proteolytic activities may be associated with larval nutrition because these stages are highly detritivorous and need to eat large amounts of food to obtain their basic nutrients. Indeed, the main peptidases expressed by larvae are thought to be involved in the processing of nutrients and have optimal activity at an alkaline $\mathrm{pH}[13,58]$. In addition, we demonstrated that larval instars exhibit a complex profile of active peptidases composed by at least eight bands of trypsin-like serine peptidases. These results are in agreement with a recent transcriptome study showing that 12 serine peptidases-like genes were preferential expressed in the larvae of Ae. aegypti $[39,59]$. The broad spectrum of enzymatic activities detected in the larvae of Ae. albopictus could be related to their survival in aquatic environments that are lacking nutrients [13,58].

In addition, the zymographic patterns of larvae from Ae. albopictus and Ae. aegypti [22] share a band of proteolytic activity with the same intensity at approximately $28 \mathrm{kDa}$. Additionally, several bands between 36 and $72 \mathrm{kDa}$ observed in the enzymatic profile of $A e$. albopictus match those of Ae. aegypti, although with different intensities. These data could indicate that (i) the expression of genes coding for some active trypsin-like serine peptidases isoforms is conserved among Aedes 


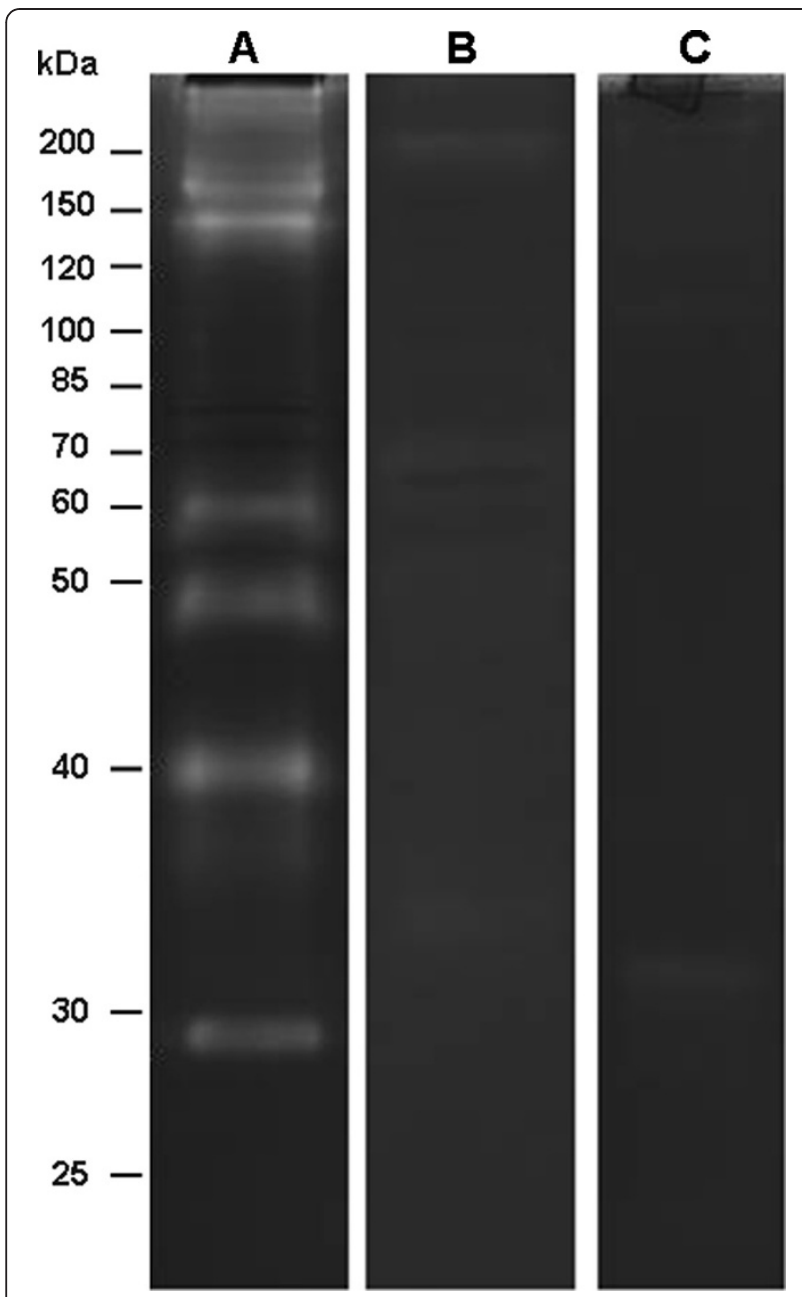

Figure 6 Effect of TLCK and PMSF on the profile of the proteolytic extracts from Ae. albopictus pupae. Proteolytic activities were detected after incubating the gels for 36 hours at $37^{\circ} \mathrm{C}$ in Tris- $\mathrm{HCl}$ buffer ( $\mathrm{pH} 7.5$ ). Enzymatic assays were performed in the absence of peptidase inhibitors (A), in the presence of $100 \mu \mathrm{M}$ TLCK (B), and in the presence of $1 \mathrm{mM}$ PMSF $(\mathbf{C})$. The numbers on the left indicate the approximate molecular masses of the peptidases $(\mathrm{kDa})$

species and (ii) that other isoforms are species-specific. In fact, this conservation is expected given the importance of these enzymes for the life cycle of these mosquitoes $[21,56,59]$. On the other hand, bands of proteolytic activities with different intensities within the same stage of development, among distinct stages and between the two species may indicate that some genes coding for trypsin are differentially expressed or that some isoforms with specific catalytic features are differentially regulated during the life cycle of the insect. Complex mechanisms regulating the expression of trypsin in insects have been previously described [39,53-56,60].

We next sought to investigate the stability of the proteolytic profile in larvae obtained from the eggs of females reared in a colony for long time periods compared with larvae hatched from eggs collected in the natural environment. Our results demonstrate that the enzymatic pattern did not change, suggesting that the qualitative expression of peptidases is stable under the experimental conditions used here. In other words, such stability suggests that the genes coding for these enzymes could be under strong selective pressure so that the proteolytic profile is maintained in both natural and colony conditions. These results indicate that inbreeding during prolonged maintenance of the colony does not alter the expression of the genes coding for the trypsinlike serine peptidases detected in zymographic assays of the larvae. In addition, such observations suggest that trypsin-like serine peptidases of Ae. albopictus could be constitutively expressed during all developmental stages.

The proteolytic profile of Ae. albopictus eggs was similar to that exhibited by the larval instars, specifically the L1 instar, in the number and intensity of bands. Three bands of enzymatic activity between 17 and $28 \mathrm{kDa}$ were observed in both the eggs and larvae, although they displayed different intensities. The similarity of the active peptidase profile observed between the eggs and L1 may be explained by the fact that the eggs were assayed at the final stage of maturation when the embryo is very similar to the young L1. In addition, the proteolytic activities from the eggs likely had lower intensity because before they hatched, the larvae were lethargic, presenting low metabolism inside the eggs.

The pupal stage exhibited a complex and stage-specific proteolytic profile, composed of six bands of activity. Compared to the larval profile, which showed activities in a wide $\mathrm{pH}$ range $(3.5-10)$, the pupal stage presented activities exclusively between pH 7.5 and 10. Peptidases from the larval extracts could be observed after 2 hours of incubation, whereas peptidases from the pupal stage were detected only after 24 hours of reaction. These observations indicate a reduction in the expression of active digestive peptidases after the last larval molt [13]. However, although pupae do not feed, serine peptidase activities could be related to the proteolysis of the remaining larval tissue during metamorphosis. In support of this idea, in Sarcophaga peregrina, a $26 \mathrm{kDa}$ trypsin protein was isolated from the corpus luteum, an organ that develops temporarily in the pupae and serves to disintegrate the gut of immature stages and reshape it to form the adult insect's gut [50,61-63].

The effect of temperature on trypsin-like serine peptidase activities from larvae was also tested. When compared to the control condition $\left(37^{\circ} \mathrm{C}\right)$, the proteolytic activities of all larval instars were susceptible to low temperatures $\left(4^{\circ} \mathrm{C}\right.$ and $\left.10^{\circ} \mathrm{C}\right)$ and highly stimulated at high temperatures $\left(50^{\circ} \mathrm{C}\right)$. Although enzymatic activity decayed at $60^{\circ} \mathrm{C}$, a clear profile could still be observed at 
this temperature. The strong decrease of proteolytic activity could be due to the thermal denaturation of the enzymes. Similar results were described for trypsin and chymotrypsin from the larvae of Tenebrio molitor $[64,65]$ and for serine peptidases from Oestrus ovis [66] and Ae. aegypti [22]. Because temperature is one of the most important environmental conditions for sustaining life on earth, the adaptation of an organism to extreme environments requires the optimization of its enzymatic repertoire. In this sense, the investigation of thermostable proteins, which are highly conserved in phylogenetically related groups of organisms, could help to identify changes in amino acid sequences that could be associated with thermal adaptation [67]. Because $A e$. aegypti and Ae. albopictus are related species that originated from different environments, a detailed study comparing the sequence and structure of the trypsin isoforms could provide important information on the molecular basis of the thermal stability of these enzymes.

\section{Conclusion}

The zymographic profiles of the preimaginal stages of Ae. albopictus are composed of a complex combination of trypsin-like serine peptidase activities that exhibit stage-specific characteristics. A comparison of the proteolytic activities during different developmental stages allowed for the detection of both qualitative and quantitative differences in trypsin activities, indicating that the serine peptidases are expressed in a stage-specific manner. In addition, we demonstrate that the proteolytic profile in larval instars is stable because larvae from the natural environment and larvae from a colony exhibited identical trypsin-like peptidase patterns. Such a phenotypic characteristic could be exploited for the characterization of other Culicidae insects.

\section{Competing interests}

The authors declare that they have no competing interests.

\section{Authors' contributions}

$J B J, L S V$ and PC designed the study. LSV, ABV, CMR, APB and GDL performed the experimental work. LSV, ABV, CMR, PC and JBJ analyzed the data and prepared the manuscript, with critical input from CB. All of the authors read and approved the final manuscript.

\section{Acknowledgements}

This work was supported by FAPEMIG (APQ-02093-09), FIOCRUZ-IOC, CNPq and CAPES. We thank Prof. Dr. Nildimar Honorio (Laboratório de Transmissores de Hematozoários of the Instituto Oswaldo Cruz) for kindly providing the insects.

\section{Author details}

'Laboratório de Biologia Molecular e Doenças Endêmicas, Instituto Oswaldo Cruz, FIOCRUZ, Rio de Janeiro, Brazil. ²Laboratório de Pesquisa em Leishmaniose, Instituto Oswaldo Cruz, FIOCRUZ, Rio de Janeiro, Brazil.

${ }^{3}$ Departamento de Engenharia de Biossistemas, Universidade Federal de São João Del Rey, Minas Gerais, Brazil.

Received: 10 October 2012 Accepted: 18 February 2013

Published: 27 February 2013

\section{References}

1. Gilotra SK, Rozeboom LE, Bhattacharya NC: Observations on possible competitive displacement between populations of Aedes aegypti Linnaeus and Aedes albopictus Skuse in Calcutta. Bull Org Mond Santé 1967, 37:437-446.

2. O'Meara GF, Evans LF Jr, Gettman AD, Cuda JP: Spread of Aedes albopictus and decline of Ae. aegypti (Diptera: Culicidae) in Florida. J Med Entomol 1995, 32:554-562.

3. Schreiber ET, Cuda JP: Evaluation of public information packets for source reduction in three socioeconomic areas of Tampa, Florida. J Am Mosa Control Assoc 1994, 10:154-162

4. Forattini OP, Marques GR, Kakitani I, de Brito M, Sallum MA: Epidemiologic significance of Aedes albopictus breeding places in bromeliads. Rev Saude Publica 1998, 32:186-188.

5. Gratz NG: Critical review of the vector status of Aedes albopictus. Med Vet Entomol 2004, 18:215-227.

6. Dieng H, Saifur GMR, Hassan AA, Salmah MRC, Boots M, Satho T, Jaal Z, AbuBakar $\mathrm{S}$ : Indoor breeding of Aedes albopictus in northern peninsular Malasya and its potential epidemiological implications. PLoS One 2010, 5:e11790.

7. Juliano SA: Species introduction and replacement among mosquitoes: interspecific resource competition or apparent competition. Ecology 1998, 79:255-268.

8. Cancrini G, Romi R, Gabrielli S, Toma L, di Paolo M, Scaramozzino P: First finding of Dirofilaria repens in a natural population of Aedes albopictus. Med Vet Entomol 2003, 17:448-451.

9. Delatte H, Desvars A, Bouétard A, Bord S, Gimonneau G, Vourc'h G, Fontenille D: Blood-feeding behavior of Aedes albopictus, a vector of Chikunguya on La Réunion. Vector Borne Zoonotic Dis 2010, 10:249-259.

10. Genchi C, Rinaldi L, Mortarino M, Genchi M, Cringoli G: Climate and Dirofilaria infection in Europe. Vet Parasitol 2009, 163:286-292.

11. Samuel PP, Krishnamoorthi R, Hamzakova KK, Aggarwal CS: Entomoepidemiological investigations on chikungunya outbreak in the Lakshadweep islands, Indian Ocean. Indian J Med Res 2009, 129:442-445.

12. Paupy C, Ollomo B, Kamgang B, Moutailler S, Rousset D, Demanou M, Hervé $J$ P, Leroy E, Simard F: Comparative role of Aedes albopictus and Aedes aegypti in the emergence of dengue and chikungunya in central Africa. Vector Borne Zoonotic Dis 2010, 10:259-266.

13. Yang YJ, Davies D: Trypsin and chymotrypsin during metamorphosis in Aedes aegypti and properties of the chymotrypsin. J Insect Physiol 1971, 17:117-131.

14. Volz J, Osta MA, Kafatos FC, Müller HM: The roles of two clip domains serine proteases in innate immune responses of the malaria vector Anopheles gambiae. J Biol Chem 2005, 280:40161-40168.

15. Xu W, Huang FS, Hao HX, Duan JH, Qiu ZW: Two serine proteases from Anopheles dirus haemocytes exhibit changes in transcript abundance after infection of an incompatible rodent malaria parasite, Plasmodium yoelli. Vet Parasitol 2006, 139:93-101.

16. Rodrigues J, Agrawal N, Sharma A, Malhotra P, Adak T, Chauhan VS, Bhatnagar RK: Transcriptional analysis of an immune-responsive serine protease from Indian malarial vector, Anopheles culicifacies. BMC Mol Biol 2007, 8:33

17. Terra WR, Ferreira $C:$ Insect digestive enzymes: properties, compartmentalization and function. Comp Biochem Physiol B Biochem Mol Biol 1994, 109b:1-62.

18. Blow DM: The tortuous story of Asp. ..His. . .Ser: Structural analysis of a-chymotrypsin. Trends Biochem Sci 1997, 22:405-408.

19. Borovsky D: Biosynthesis and control of mosquito gut proteases. IUBMB Life 2003, 55:435-441.

20. Hedstrom L: Serine protease mechanism and specificity. Chem Rev 2002, 102:4501-4524.

21. Ho BC, Khoo HG, Chew LM, Wong KP, Ewert A: Food ingestion and digestive enzymes in larval Aedes aegypti and Aedes albopictus (Diptera: Culicidae). J Med Entomol 1992, 29:960-964.

22. Mesquita-Rodriques C, Saboia-Vahia L, Cuervo P, D'Ávila-Levy CM, Honorio $N A$, Domont $G B$, de Jesus JB: Expression of trypsin-like serine peptidases in preimaginal stages of Aedes aegypti (Diptera: Culicidae). Arch Insect Biochem Physiol 2011, 76:223-235.

23. Borges-Veloso A, Saboia-Vahia L, Cuervo P, Pires RC, Britto C, Fernandes N, D'Ávila-Levy CM, De Jesus JB: Proteolytic profiling and comparative analyses of active trypsin-like serine peptidases in preimaginal stages of Culex quinquefasciatus. Parasit Vectors 2012, 5:123. 
24. Pires FA, Moya-Borja GE, Barreira JD, Pinho RT, Alves CR: The main proteinases in Dermatobia hominis second and third instars larvae are serine-proteinases. Vet Parasitol 2007, 145:326-331.

25. Fazito-do-Vale V, Pereira MH, Gontijo NF: Midgut $\mathrm{pH}$ profile and protein digestion in the larvae of Lutzomyia longipalpis (Diptera: Psychodidae). J Insect Physiol 2007, 53:1151-1159.

26. Tamaki FK, Padilha MH, Pimentel AC, Ribeiro AF, Terra WR: Properties and secretory mechanism of Musca domestica digestive chymotrypsin and its relation with Drosophila melanogaster homologs. Insect Biochem Mol Biol 2012, 42:482-490.

27. Cuervo P, Mesquita-Rodriques C, D'Ávila-Levy CM, Britto C, Pires FA, Gredilha $R$, Alves $C R$, Jesus JB: Serine protease activities in Oxysarcodexia thornax (Walker) (Diptera: Sarcophagidae) first instar larva. Mem Inst Oswaldo Cruz 2008, 103:504-506

28. Shahabuddin M, Toyoshima T, Aikawa M, Kaslow DC: Transmissionblocking activity of a chitinase inhibitor and activation of malarial parasite chitinase by mosquito protease. Proc Natl Acad Sci USA 1993, 90:4266-4270.

29. Shahabuddin M, Costero A: Spatial distribution of factors that determine sporogonic development of malaria parasites in mosquitoes. Insect Biochem Mol Biol 2001, 31:231-240.

30. Gill SS: Mechanism of action of Bacillus thuringiensis toxins. Mem Inst Oswaldo Cruz 1995, 90:69-74.

31. Telleria EL, de Araújo AP, Secundino NF, D'Avila-Levy CM, Traub-Csekö YM: Trypsin-like serine proteases in Lutzomyia longipalpis: expression, activity and possible modulation by Leishmania infantum chagasi. PLoS One 2010, 5:e10697.

32. Ghosh A, Edwards MJ, Jacobs-Lorena M: The journey of the Malaria Parasite in the Mosquito: Hopes for the New Century. Parasitol Today 2000, 16:5.

33. Ludwig GV, Christensen BM, Yuill TM, Schultz KT: Enzyme processing of La Crosse virus glycoprotein G1: a bunyavirus-vector infection model. Virology 1989, 171:108-113.

34. Mertens PP, Burroughs JN, Walton A, Wellby MP, Fu H, O'Hara RS, Brookes SM, Mellor PS: Enhanced infectivity of modified bluetongue virus particles for two insect cell lines and for two Culicoides vector species. Virology 1996, 217:582-593.

35. Molina-Cruz A, Gupta L, Richardson J, Bennett K, Black W 4th, Barillas-Mury C: Effect of mosquito midgut trypsin activity on dengue-2 virus infection and dissemination in Aedes aegypti. Am J Trop Med Hyg 2005, 72:631-637.

36. Honório NA, Silva Wda C, Leite PJ, Gonçalves JM, Lounibos LP, Lourenço-de -Oliveira R: Dispersal of Aedes aegypti and Aedes albopictus (Diptera: Culicidae) in an urban endemic dengue area in the State of Rio de Janeiro, Brazil. Mem Inst Oswaldo Cruz 2003, 98:191-198.

37. Consoli RAGB, Lourenço-de-Oliveira R: Principais mosquitos de importância sanitária no Brasil. Fiocruz: Rio de Janeiro: Brasil Press; 1994:225-250.

38. Brackney DE, Isoe J, Black WC IV, Zamora J, Foy BD, Miesfeld RL, Olson KE: Expression profiling and comparative analyses of seven midgut serine proteases from the yellow fever mosquito, Aedes aegypti. J Insect Physiol 2010, 56:736-744.

39. Soares TS, Watanabe RMO, Lemos FJA, Tanaka AS: Molecular characterization of genes encoding trypsin-like enzymes from Aedes aegypti larvae and identification of digestive enzymes. Gene 2011, 489:70-75.

40. Isoe J, Rascón AA Jr, Kunz S, Miesfeld RL: Molecular genetic analysis of midgut serine proteases in Aedes aegypti mosquitoes. Insect Biochem Mol Biol 2009, 39:903-912.

41. Holt RA, Subramanian GM, Halpern A, Sutton GG, Charlab R, Nusskern DR, Wincker P, Clark AG, Ribeiro JM, Wides R, Salzberg SL, Loftus B, Yandell M, Majoros WH, Rusch DB, Lai Z, Kraft CL, Abril JF, Anthouard V, Arensburger P, Atkinson PW, Baden $\mathrm{H}$, de Berardinis V, Baldwin D, Benes V, Biedler J, Blass C, Bolanos R, Boscus D, Barnstead M, et al: The genome sequence of the malaria mosquito Anopheles gambiae. Science 2002, 298:129-149.

42. Nene V, Wortman JR, Lawson D, Haas B, Kodira C, Tu ZJ, Loftus B, Xi Z, Megy K, Grabherr M, Ren Q, Zdobnov EM, Lobo NF, Campbell KS, Brown SE, Bonaldo MF, Zhu J, Sinkins SP, Hogenkamp DG, Amedeo P, Arensburger P, Atkinson PW, Bidwell S, Biedler J, Birney E, Bruggner RV, Costas J, Coy MR, Crabtree J, Crawford M, et al: Genome sequence of Aedes aegypti, a major arbovirus vector. Science 2007, 316:1718-1723

43. Arensburger P, Megy K, Waterhouse RM, Abrudan J, Amedeo P, Antelo B, Bartholomay L, Bidwell S, Caler E, Camara F, Campbell CL, Campbell KS, Casola C, Castro MT, Chandramouliswaran I, Chapman SB, Christley
S, Costas J, Eisenstadt E, Feschotte C, Fraser-Liggett C, Guigo R, Haas B, Hammond M, Hansson BS, Hemingway J, Hill SR, Howarth C, Ignell R, Kennedy RC, et al: Sequencing of Culex quinquefasciatus establishes a platform for mosquito comparative genomics. Science 2010, 330:86-88.

44. Wu DD, Guo-Dong W, Irwin DM, Zhang YP: A profound role for the expansion of trypsin-like serine protease family in the evolution of hematophagy in mosquito. Mol Biol Evol 2009, 26:2333-2341.

45. Zdobnov EM, von Mering C, Letunic I, Torrents D, Suyama M, Copley RR, Christophides GK, Thomasova D, Holt RA, Subramanian GM, Mueller HM, Dimopoulos G, Law JH, Wells MA, Birney E, Charlab R, Halpern AL, Kokoza E, Kraft CL, Lai Z, Lewis S, Louis C, Barillas-Mury C, Nusskern D, Rubin GM, Salzberg SL, Sutton GG, Topalis P, Wides R, Wincker P, et al: Comparative genome and proteome analysis of Anopheles gambiae and Drosophila melanogaster. Science 2002, 298:149-159.

46. Borovsky D, Schlein Y: Quantitative determination of trypsin-like and chymotrypsin-like enzymes in insects. Arch Insect Biochem Physiol 1988 8:249-260

47. Gorman MJ, Paskewitz SM: Serine proteases as mediators of mosquito immune responses. Insect Biochem Mol Biol 2001, 31:257-262.

48. Rawlings ND, Barrett AJ: Families of serine peptidases. Methods Enzymol 1994, 244:19-61.

49. Borovsky D: Trypsin-modulating oostatic factor: a potential new larvicide for mosquito control. J Exp Biol 2003, 206:3869-3875.

50. Nakajima Y, Tsuji Y, Homma K, Natori S: A novel protease in the pupal yellow body of Sarcophaga peregrina (flesh fly). Its purification and CDNA cloning. J Biol Chem 1997, 272:23805-23810.

51. Neurath H: Evolution of proteolytic enzymes. Science 1984, 224:350-357.

52. Hedstrom L: An overview of serine proteases. Curr Protoc Protein Sci 2002, $21: 21.10$.

53. Felix CR, Betschart B, Billingsley PF, Freyvogel TA: Post-feeding induction of trypsin in the midgut of Aedes aegypti (Diptera: Culicidae) is separable into two cellular phases. Insect Biochem 1991, 21:197-203.

54. Noriega FG, Wells MA: A molecular view of trypsin synthesis in the midgut of Aedes aegypti. J Insect Physiol 1999, 45:613-620.

55. Noriega FG, Edgar KA, Bechet R, Wells MA: Midgut exopeptidase activities in Aedes aegypti are induced by blood feeding. J Insect Physiol 2002, 48:205-212.

56. Borovsky D, Meola SM: Biochemical and cytoimmunological evidence for the control of Aedes aegypti larval trypsin with Aea-TMOF. Arch Insect Biochem Physiol 2004, 55:124-139.

57. Tabouret G, Bret-Bennis L, Dorchies P, Jacquiet P: Serine protease activity in excretory-secretory products of Oestrus ovis (Diptera: Oestridae) larvae. Vet Parasitol 2003, 114:305-314.

58. Dadd RH: Alkalinity within the midgut of mosquito larvae with alkalineactive digestive enzymes. J Insect Physio/ 1975, 21:1847-1853.

59. Venancio TM, Cristofoletti PT, Ferreira C, Verjovski-Almeida S, Terra WR: The Aedes aegypti larval transcriptome: a comparative perspective with emphasis on trypsins and the domain structure of peritrophins. Insect Mol Biol 2009, 18:33-44.

60. Noriega FG, Wang XY, Pennington JE, Barillas-Mury CV, Wells MA: Early trypsin, a female-specific midgut protease in Aedes aegypti: isolation, amino terminal sequence determination, and cloning and sequencing of the gene. Insect Biochem Mol Biol 1996, 26:119-126.

61. Yano T, Takahashi N, Kurata S, Natori S: Regulation of the expression of cathepsin B in Sarcophaga peregrina (flesh fly) at the translational level during metamorphosis. Eur J Biochem 1995, 234:39-43.

62. LeMosy EK: Proteolytic regulatory mechanisms in the formation of extracellular morphogen gradients. Birth Defects Res C Embryo Today 2006, 78:243-255.

63. Philip JM, Fitches E, Harrison RL, Bonning B, Gatehouse JA: Characterisation of functional and insecticidal properties of a recombinant cathepsin Llike proteinase from flesh fly (Sarcophaga peregrina), which plays a role in differentiation of imaginal discs. Insect Biochem Mol Biol 2007, 37:589-600.

64. Elpidina EN, Tsybina TA, Dunaevsky YE, Belozersky MA, Zhuzhikov DP, Oppert B: A chymotrypsin-like proteinase from the midgut of Tenebrio molitor larvae. Biochimie 2005, 87:771-779.

65. Tsybina TA, Dunaevsky YE, Belozersky MA, Zhuzhikov DP, Oppert B, Elpidina EN: Digestive proteinases of yellow mealworm (Tenebrio molitor) larvae: purification and characterization of a trypsin-like proteinase. Biochemistry (Mosc) 2005, 70:300-305. 
66. Angulo-Valadez CE, Cepeda-Palacios R, Ascencio F, Jacquiet P, Dorchies P, Romero MJ, Khelifa RM: Proteolytic activity in salivary gland products of sheep bot fly (Oestrus ovis) larvae. Vet Parasitol 2007, 149:117-125.

67. Thomas T, Cavicchioli R: Archaeal cold-adapted proteins: structural and evolutionary analysis of the elongation factor 2 proteins from psychrophilic, mesophilic and thermophilic methanogens. FEBS Lett 1998, 439:281-286.

doi:10.1186/1756-3305-6-50

Cite this article as: Saboia-Vahia et al:: Trypsin-like serine peptidase

profiles in the egg, larval, and pupal stages of Aedes albopictus. Parasites \& Vectors 2013 6:50.

\section{Submit your next manuscript to BioMed Central and take full advantage of:}

- Convenient online submission

- Thorough peer review

- No space constraints or color figure charges

- Immediate publication on acceptance

- Inclusion in PubMed, CAS, Scopus and Google Scholar

- Research which is freely available for redistribution 